\title{
Thermal behavior of DGEBA (Diglycidyl Ether of Bisphenol A) adhesives and its influence on the strength of joints
}

\author{
Julina PB Souza and Joao ML Reis ${ }^{*}$
}

\author{
* Correspondence: jreis@mec.uff.br \\ Laboratory of Theoretical and Applied \\ Mechanics - LMTA, Mechanical \\ Engineering Post Graduate Program - \\ PGMEC, Universidade Federal \\ Fluminense - UFF, Rua Passo da \\ Pátria, 156, Bloco E, sala 216, Niterói, \\ Rio de Janeiro, Brazil
}

\begin{abstract}
Adhesives, especially epoxies, are widely used as joints, repairs and corrosion protection in the petroleum onshore and offshore industry. Performance temperature is a key factor for such material. Mainly they are designed by the thermal properties but when they are in real service operation the behavior changes drastically. In this work, three different epoxy adhesives used in the offshore industry are characterized by DSC, DMA and TGA methods. The main objective is to verify if thermo mechanical tests on adhesives produces enough information to use in temperature service situation instead of test single lap joints (SLJ) at different temperatures. From the tests results it can be seen that adhesive SLJ should be tested in order to proper service design.
\end{abstract}

Keywords: Epoxy; Glass transition temperature; DSC; DMA; TGA; Single lap joints

\section{Background}

Oil exploitation presents new challenges to offshore engineering and operating companies. Several recent technological achievements, especially those related to applications in such diverse relevant areas only became possible after the advent of structural adhesives. Polymer adhesives industry is currently placing emphasis on protective coatings, structural applications and reparability as part of the incorporation of such material in oil production systems. Epoxy adhesives are the most used material for such applications.

Some of the characteristics of epoxy resins are high chemical and corrosion resistance, good mechanical and thermal properties, outstanding adhesion to various substrates, low shrinkage upon cure, good electrical insulating properties, and the ability to be processed under a variety of conditions [1-4]. Depending on the specific needs for certain physical and mechanical properties, combinations of choices of epoxy resin and curing agents can usually be formulated to meet the market demands. However, in terms of structural applications, epoxy resins are usually brittle and temperature sensitive. In fact, temperature is a key factor concerning offshore applications. One of the most important parameter related to temperature is the one associated with the glass transition temperature $(\mathrm{Tg})$ [5]. The basis of this transition is the onset of coordinated molecular motion in the polymer chain. In the region of $(\mathrm{Tg})$, the polymer softens, and the modulus drops three orders of magnitude. The polymer becomes rubbery [6] and

(c) 2013 Souza and Reis; licensee Springer. This is an open access article distributed under the terms of the Creative Commons Attribution License (http://creativecommons.org/licenses/by/2.0), which permits unrestricted use, distribution, and reproduction in any medium, provided the original work is properly cited. 
when $T g$ is exceeded, it can compromise significantly the mechanical properties of the material taking as the operational limit temperature. All amorphous (non-crystalline or semi-crystalline) materials will yield a $T g$ during heating and $T g$ is the main characteristic transformation temperature of the amorphous phase. The glass transition event occurs when a hard, solid, amorphous material or component undergoes its transformation to a soft, rubbery, liquid phase. $\mathrm{Tg}$ is a valuable characterization parameter associated with a material and can provide very useful information regarding the endues performance of a product.

Many researchers have studied the effect of temperature on joints. Da Silva and Adams $[7,8]$ studied mixed adhesive joints for low and high temperatures to improve stress distribution and increase strength. Test temperatures ranged from $-55^{\circ} \mathrm{C}$ to $200^{\circ} \mathrm{C}$.

Grant et al. [9] performed tests in SLJ and $\mathrm{T}$ joints at $-40^{\circ} \mathrm{C},+20^{\circ} \mathrm{C}$ and $+90^{\circ} \mathrm{C}$ to investigate the possibility of substitute spot-welding by structural adhesive in the automotive industry. Banea et al. $[10,11]$ investigated the effect of temperature on epoxy adhesives and single lap joints. They found that at temperatures below $T g$, the lap shear strength of SLJs increased, while at temperatures above $T g$, a drastic drop in the lap shear strength was observed. The performance of an adhesive joint depends critically upon the nature of the adhesion interface. Joints performance will very much depend on differences in thermal expansion characteristics between adhesive and substrate.

In this paper three commercial adhesives were tested. Mainly these adhesives are used in petroleum industry as pipeline integrity repair, inshore and offshore. These applications can reach up to $80^{\circ} \mathrm{C}$ and their properties must be studied to ensure the structural integrity of such structures. The objective of this study is to characterize these epoxy adhesives by means of DSC, DMA and TGA, compare to the results obtained in single lap joints (SLJ) manufactured with the same adhesives [12] tested at different temperatures and verify if thermo mechanical tests on the adhesives produces enough information to use in temperature service situation. Nowadays, service and maintenance companies are designing and applying epoxy adhesives based on their thermo mechanical properties, neglecting their behavior when bonded to different materials and used at temperatures higher than laboratory room temperatures. SLJ estimates the real adhesive application.

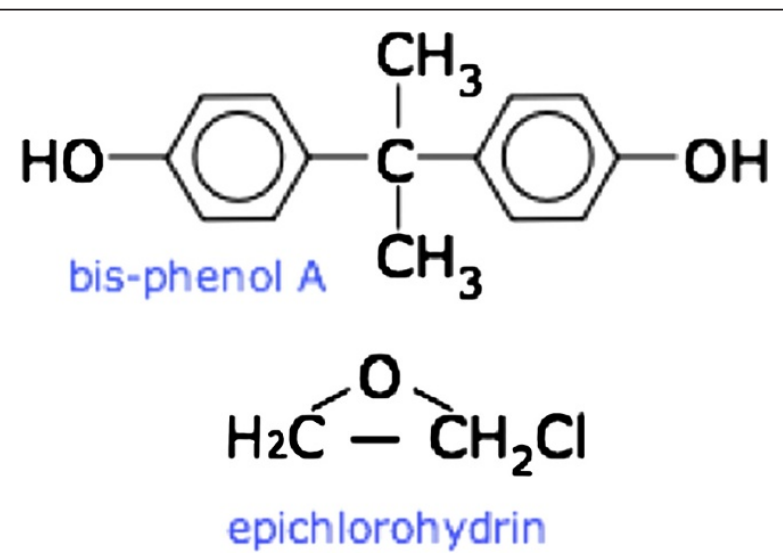

Figure 1 Chemical structure of bisphenol A and epichlorohydrin. 
Table 1 Technical data of ARC 858

\begin{tabular}{lll}
\hline Technical data & & \\
\hline Density after cure $(\mathrm{g} / \mathrm{cm} 3)$ & & 1.6 \\
Tensile strength $(\mathrm{MPa})$ & ASTM D 638 & 20.7 \\
Shear bond strength $(\mathrm{MPa})$ & ASTM D 1002 & 14.7 \\
Maximum temperature $(\mathrm{OC})$ & $100 \%$ humidity & 70 \\
& $0 \%$ humidity & 160 \\
\hline
\end{tabular}

\section{Methods}

Materials

The selected adhesives have the same base, diglycidyl ether of bisphenol A (DGEBA), an epoxy resin product of the reaction between bisphenol A and epichlorohydrin with a basic catalyst. Figure 1 shows the chemical structure of these two substances.

\section{ARC858 adhesive}

Produced by A. W. Chesterton Company, Boston (USA), ARC 858 is an epoxy adhesive with ceramic particles (silicon carbide) and a filler (titanium dioxide), highly resistance to wear and corrosion, its properties, after curing, are in the table below. The technical data provided by the manufacturer are presented in Table 1 .

\section{Belzona 1111 adhesive}

The second studied product, produced by Belzona INC, Harrogate (UK), is also an epoxy resin, but with DGEBF (diglycidyl ether of bisphenol F) addition and filled with modified silica and talc, the last to give volume to the product. Belzona 1111 technical information provided by the manufacturer are summarized in Table 2.

\section{MultiMetall (MM) SteelCeramic (SS) adhesive}

Produced by MultiMetall (MM), Versen Germany, SteelCeramic (SS) is a two-component adhesive having two types of hardeners: a yellow, used in this study, which provides better mechanical properties; and a red hardener, applicable in emergency repairs because it gives a shorter cure time. The technical data provided by the manufacturer for yellow hardener are presented in Table 3.

\section{Experimental setup}

This study uses the glass transition temperature $(T g)$ for estimating the maximum operating temperature of the adhesives studied. Thus, for each type of analysis, a change in the graph has been determined to determine the $\mathrm{Tg}$. Samples from each type

Table 2 Technical data of Belzona 1111

\begin{tabular}{lll}
\hline Technical data & & \\
\hline Density after cure $(\mathrm{g} / \mathrm{cm} 3)$ & & 12.5 \\
Shear bond strength $(\mathrm{MPa})$ & ASTM D1002 & 18.6 \\
Compressive strength (MPa) & ASTM D605 & 89.6 \\
Flexural strength (MPa) & ASTM D790 & 62.1 \\
Maximum temperature (oC) & $100 \%$ humidity & 93 \\
& $0 \%$ humidity & 200 \\
\hline
\end{tabular}


Table 3 Technical Data of MultiMetall - MM Steelceramic -SS

\begin{tabular}{|c|c|c|}
\hline Technical data & & \\
\hline Density after cure $(\mathrm{g} / \mathrm{cm} 3)$ & & 2.4 \\
\hline Tensile strength (MPa) & ASTM D 638 & 30.4 \\
\hline Operation temperature range (oC) & & -150 to 280 \\
\hline
\end{tabular}

of adhesive were made according to manufacturer recommendation to perform DSC, DMA and TG analysis.

\section{Thermogravimetric analysis (TGA)}

The analysis by thermogravimetry (TGA) were performed according to ASTM E1131 in equipment Shimadzu, model DTG - $60 \mathrm{H}$. The temperature range chosen was from ambient $(26 \mathrm{oC} \pm 2)$ up to $500 \mathrm{oC}$, with heating rate of $5 \mathrm{oC} / \mathrm{min}$, using $50 \mathrm{ml} / \mathrm{min}$ pure nitrogen as carrier gas. As in previous analyses, three samples from each adhesive were prepared to perform the TGA analysis. For each sample aluminum pans suitable for TGA analyzers were filled with aprox. $10 \mathrm{mg}$ of each adhesive in small pieces and introduced in the TGA equipment.

\section{Differential Scanning Calorimetry (DSC)}

The DSC analyses were performed using a Shimadzu equipment DSC - 60A, according to ASTM D 3418. A preliminary thermal cycle by heating the sample at a rate of $20^{\circ} \mathrm{C} / \mathrm{min}$ from at least $50^{\circ} \mathrm{C}$ below to $30^{\circ} \mathrm{C}$ above the decompose temperature to erase previous thermal history was performed [13]. The temperature ranges for each material studied, are presented in Table 4. Three samples from each manufacturer were tested in order to obtain an average value.

\section{Dynamic Mechanical Analysis (DMA)}

The DMA analyzes were performed with Perkin Elmer Thermal Analysis. The equipment was operated in three bending point mode at a frequency of $1 \mathrm{~Hz}$, heating rate of $50 \mathrm{C} / \mathrm{min}$, with a temperature range from 0 to $180 \mathrm{oC}$, according ASTM D7028. The samples approximate dimensions were $22 \times 6 \times 2 \mathrm{~mm}^{3}$. The storage modulus ( $\mathrm{E}^{\prime}$ ), loss modulus $\left(E^{\prime \prime}\right)$ and $\tan \delta$ versus temperature $\left({ }^{\circ} \mathrm{C}\right)$ curves were recorded. Three samples from each adhesive were tested dynamically.

\section{Results and discussion}

TGA test results

TGA analyses were performed in order to observe the thermal decomposition of the composites, especially the relation about the different filler between them.

As the base of the adhesives is the same, is expected that, since the matrix decomposition residue should be the chemically identical, the mass residual difference in the thermal decomposition of these adhesives is a result of the difference between the

Table 4 DSC temperature range

\begin{tabular}{ll}
\hline Product & Temperature range \\
\hline ARC858 & $230 \mathrm{C}$ to $850 \mathrm{C}$ \\
Belzona 1111 & $230 \mathrm{C}$ to $830 \mathrm{C}$ \\
MultiMetall- MM SteelCeramic- SS & $300 \mathrm{C}$ to $150 \circ \mathrm{C}$ \\
\hline
\end{tabular}




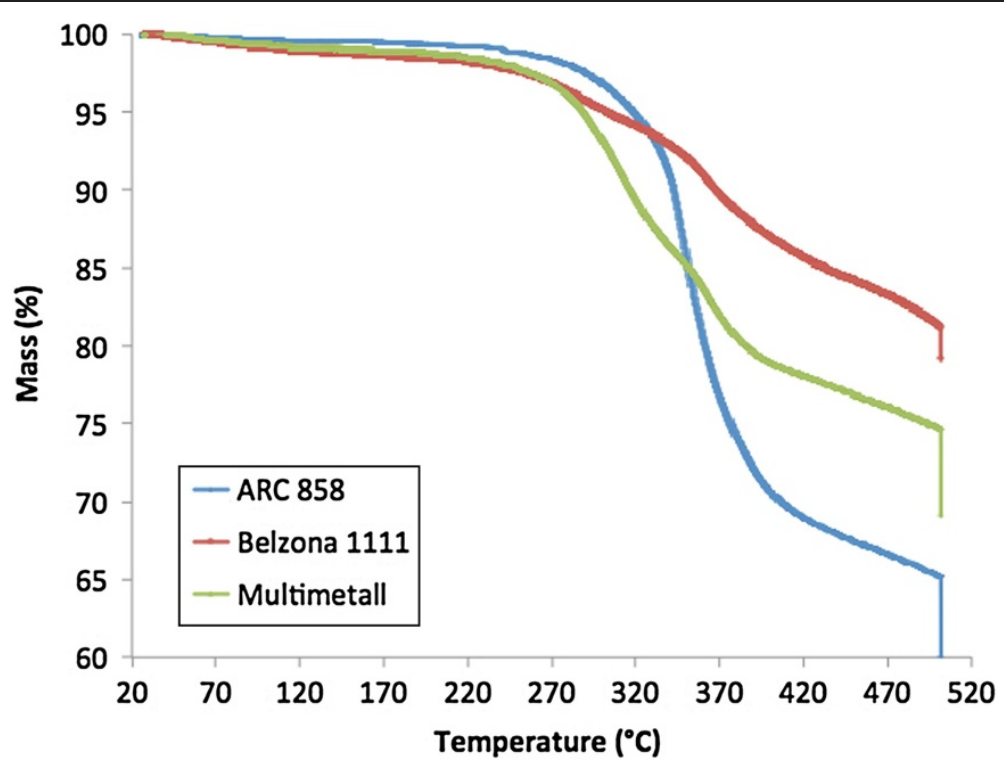

Figure 2 TGA results of all tested adhesives.

fillers and the mass fraction of filler added to each material. Figure 2 displays the TGA results of all tested adhesives.

ARC 858 has thermal decomposition curve typical of a pure epoxy polymer. As silica has a melting point higher than the temperature applied to the material, the decomposition occurred only in the epoxy matrix.

The Belzona 1111 is a composite adhesive composed by a copolymer matrix of DGEBA and DGEBF. The changes in thermo-decomposition curve are due to the overlap between the decomposition curves of each polymer while the residual mass is a result of the fillers applied to the adhesive by the manufacturer; include talc, which is known to be stable up to high temperatures.

In the latter adhesive, Multimetall MM Steelceramic SS, the decomposition curve shows pure homopolymer characteristics, as in ARC 858 curve; however, the higher residual mass suggests that the adhesive has greater amount of filler, which influences the outcome of the study, more particularly the glass transition temperature.

\section{DSC results}

In the analysis of Differential Scanning Calorimetry (DSC) three samples of each product were measured. Table 5 presents all results from the tested adhesives.

Table $5 \mathrm{Tg}$ temperature measure by DSC from all tested adhesives

\begin{tabular}{lccc}
\hline Adhesive/Temperature $\left({ }^{\circ} \mathbf{C}\right)$ & ARC 858 & BELZONA 1111 & MM - SS \\
\hline $\operatorname{Tg} 1$ & 66.8 & 76.0 & 88.5 \\
$\operatorname{Tg} 2$ & 73.6 & 71.8 & 87.7 \\
$\operatorname{Tg} 3$ & 68.5 & 74.7 & 92.2 \\
Average & 69.5 & 74.2 & 89.5 \\
St. Dev. & 2.5 & 2.2 & 2.4 \\
\hline
\end{tabular}


Analyzing the DSC tests of ARC 858 adhesive an average of $69.5^{\circ} \mathrm{C}$ in the $\mathrm{Tg}$ was observed, Belzona 1111 adhesive displayed an average $\mathrm{Tg}$ of $74.2^{\circ} \mathrm{C}$ and Multimetall SteelCeramic adhesive reports an average $T g$ of $89.5^{\circ} \mathrm{C}$, which is the highest $\mathrm{Tg}$ temperature observed. Low standard deviation was calculated, $(<4 \%)$ indicating low variation between test results.

Figure 3 displays typical test results of the second run DSC analysis for ARC 858, Belzona 1111 and MultiMetall - MM Steelceramic - SS. According to ASTM D 3418 [13], the test was composed by three sections: first heat curve, to erase previous thermal history, or post-cure process; cooling, that can be used to know the crystallization temperature, for semi-crystalline polymers; and the second heat step, which was used in this paper to provide the glass transition temperature for each adhesive. These second heat program for each adhesive composes the Figure 3 below.

It can be seen in Figure 3 for Belzona and Multimetall, even the first heat step discharge, slightly post-cure effect. But, in all tested adhesives, including ARC 858, a very clear marked change in the baseline corresponding to $\mathrm{Tg}$ temperature can be reported. So, the post-cure observed can be ignored. The glass transition was obtained in the mid-point of the transition, as recommended by ASTM D 3418. Although the in curve of Multimetall adhesive can be observed, after $\mathrm{Tg}$, an endothermic transformation that was disregarded for not being the object of study of this paper.

\section{DMA results}

The $T g$ measured by Dynamic Mechanical Analysis (DMA) in all tested adhesives, ARC 858, Belzona 1111 and Multimetall-MM StellCeramic-SS is presented in Table 6.

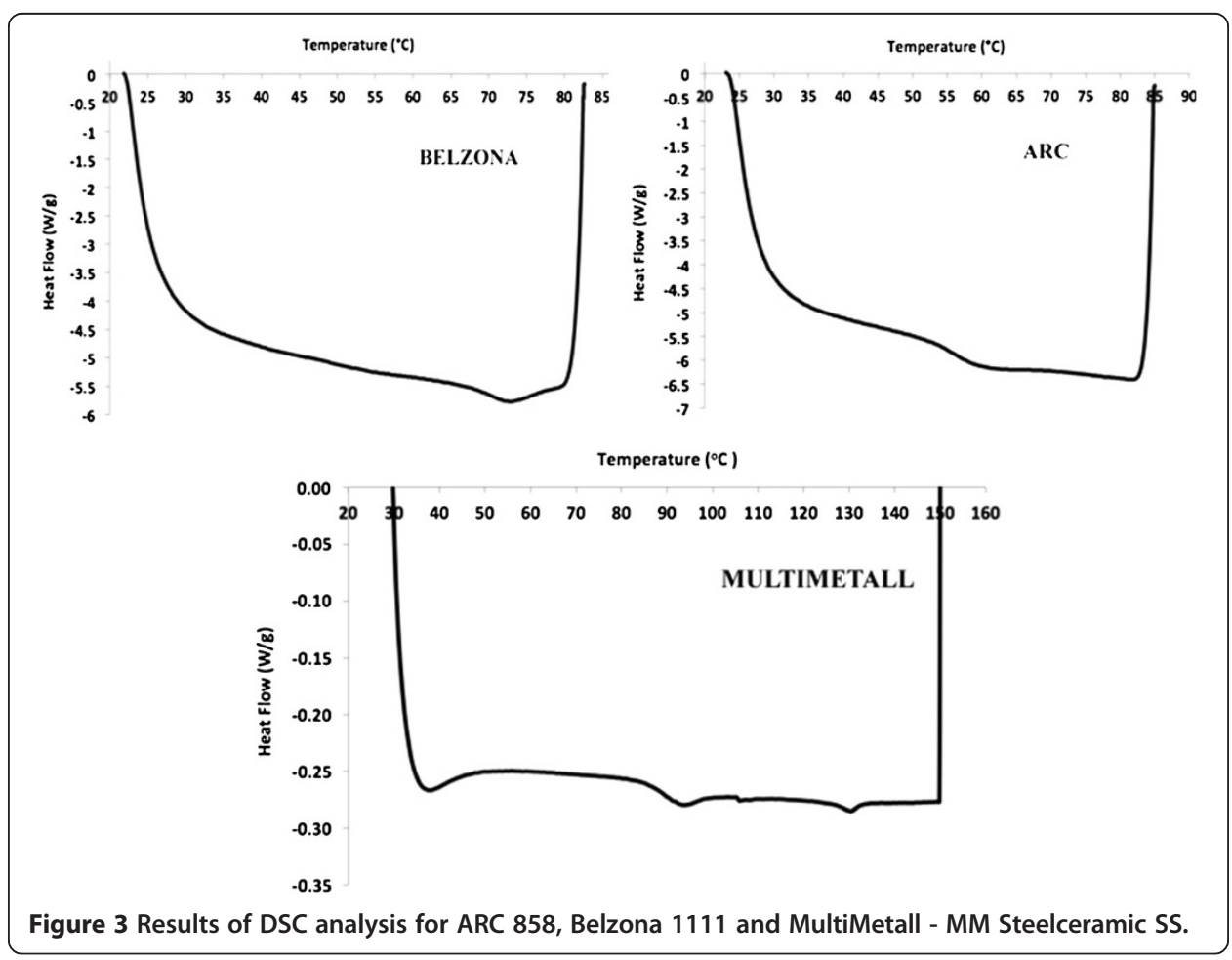


Table $6 \mathrm{Tg}$ measure by DMA from all tested adhesives

\begin{tabular}{lccc}
\hline Adhesive/Temperature $\left({ }^{\circ} \mathbf{C}\right)$ & ARC 858 & BELZONA 1111 & MultiMetall- MM SteelCeramic- SS \\
\hline $\operatorname{Tg} 1$ & 74.6 & 82.6 & 98.4 \\
$\mathrm{Tg} 2$ & 72.3 & 84.0 & 99.4 \\
$\mathrm{Tg} 3$ & 80.2 & 85.7 & 96.3 \\
Average & 77.3 & 84.1 & 98.0 \\
St. Dev. & 2.9 & 1.6 & 1.3 \\
\hline
\end{tabular}

According to Table 6 it can be seen, as reported by the DSC analysis, that ARC 858 displays the lowest $\mathrm{Tg}$ temperature, $77.3^{\circ} \mathrm{C}$ in average, and MultiMetall- MM SteelCeramic- SS the highest, $98.0^{\circ} \mathrm{C}$. Belzona 1111 presented a $\operatorname{Tg}$ of $84.1^{\circ} \mathrm{C}$. This behavior is expected, since the $\mathrm{Tg}$ is directly connected to the filler (type and fraction) used, their superficial interaction with the matrix hinders polymer chain motion, raising Tg. ARC 858 adhesive has the lowest amount of filler while Multimetall adhesive has the highest, between these three adhesives tested.

Figure 4 display curves of $E^{\prime \prime}$ and $E^{\prime}$, in GPa, versus temperature $(\mathrm{oC})$ and the curve of $\tan \delta$ versus temperature (oC) for ARC 858, Belzona 1111 and Metal-MM Steelceramic SS. ASTM D7028 describes two different forms to determinate $\mathrm{Tg}$. The first and most recommended was the intersection of two tangent lines from logarithm storage modulus curve. In this study, was used the second possibility: determine the glass transition temperature from the peak of the $\tan \delta$ vs. temperature curves, due to the difficulties to obtain the curve $E^{\prime}$ consistently, because of composite systems, such as the adhesives studied, influences the storage modulus reduction when the particulate filler affects the molecular motion of the polymer matrix.

According to Figure 4 it can be seen a defined $T g$, point at the peak of the $\tan \delta$ vs. temperature.

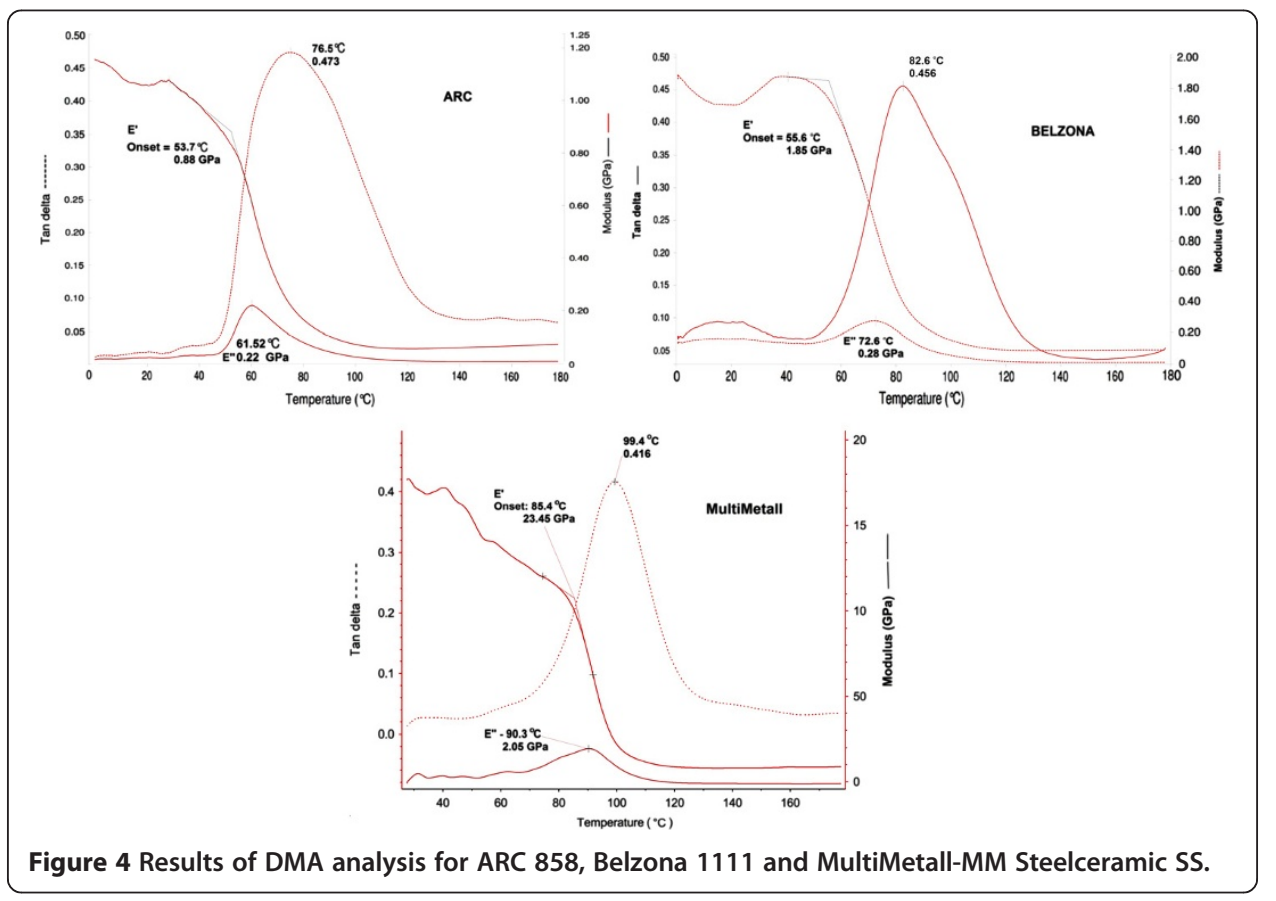


It is possible to notice a difference of 10 percent, approximately, between the $\mathrm{Tg}$ values measured by DSC and DMA for each of the ARC 858 samples and Belzona 1111. Barral et al. [14] assigns the highest value for the analyses by high-DMA measurements to the differences in the frequency for each analysis. This is because the dynamic analysis by DMA (heating rate ones), have a residual heat of reaction, thus masking the real value of the glass transition temperature.

\section{Comparison with single lap joints (SLJ) strength}

The comparison between SLJ strength tested at different temperatures is important to define which tests are the most significant to determine service conditions of these materials when used in bonded joints or polymeric repairs. Nowadays a significant use of such polymeric materials is reported especially in the oil industry as welding substitute and pipeline repair system.

The results of SLJ tests joints were obtained from previous studies of da Costa Mattos $[15,16]$ and Osanai [12] and compared to DSC and DMA results. All tested adhesives in this work were prepared at the same time, from the same batch, with same conditions, as the compared papers, to avoid unexpected influence of experimental parameters changes on joints behavior.

Initially it was expected that the glass transition temperature of these materials coincide with the temperature at which maximum force at rupture joints to fall in the range of $1000 \mathrm{~N}$. It was expected that the glass transition temperature was the temperature that such loss of strength in the SLJ was observed.

The temperatures reported in the SLJ tensile test are compared to $\mathrm{Tg}$ determined by DSC and DMA in Figure 5.

From Figure 5 it can be seen that the SLJ manufactured with ARC 858 have lower temperature resistance when compared to $T g$ measured by DSC and DMA analyses. It can be noticed that for Belzona 1111 adhesive, the maximum temperature strength of SLJs are similar to the $\mathrm{Tg}$ measured by DSC and DMA and for Multimetall MM SteelCeramic SS a significant difference is observed, close to $50 \%$. This comparison shows

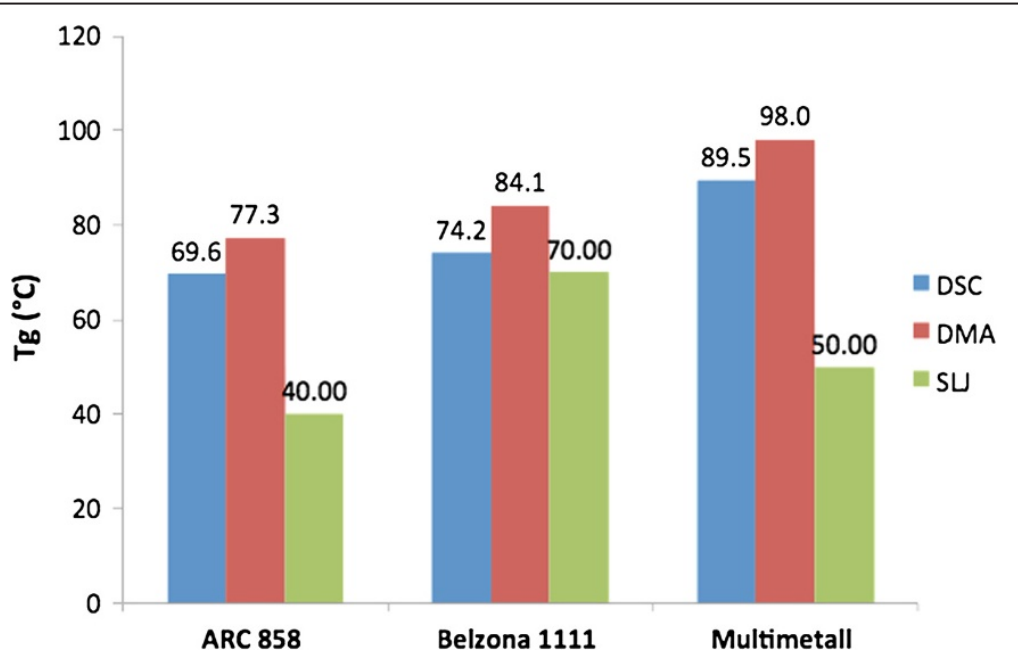

Figure 5 Comparison between DSC, DMA and SLJ strength results of all tested adhesives. 
that the service temperature of polymer composites when used as adhesives cannot be determined only by thermal analyses since the joint resistance is not solely dependent of the adhesive temperature resistance, but is also outcome of the adhesion forces between the adhesive and the substrate, this last a function of temperature as well.

\section{Conclusions}

Analyzing the results presented in this paper can be concluded that:

- For the ARC 858 a large variability between the results of the analysis shows that the material, despite having a similar behavior of a polymer without filler, does not allow a design of SLJ using the glass transition temperature as a parameter for determination of the upper limit service temperature, because the SLJ presented much lower temperature resistance compared to the results of thermal analysis by DSC and DMA.

- Belzona 1111 presented a good coherence in results, with a slight variation of $\mathrm{Tg}$ between the thermal analysis and the result coincided with the resistance loss of single lap joints in temperature.

- For material Multimetall MM SteelCeramic SS, as for ARC 858, the glass transition temperature ( $\mathrm{Tg}$ ) by DSC and DMA were much higher than the temperature in the SLJ.

With such large differences between the thermo-analyses and SLJ samples, to maintain the integrity of the repair or polymeric SLJs using these adhesives, it is suggested that the maximum service temperature of the adhesive is, on average, $40^{\circ} \mathrm{C}$ lower than the $T g$ measured by thermo analysis.

Service and maintenance companies are designing their adhesives temperature applications based on thermo mechanical analysis. This work shows that singe lap joins tests at different service temperatures cannot be neglect when epoxy adhesives are intended to be used in field applications.

Competing interests

The authors declare that they have no competing interests.

Authors' contributions

J.P.B.S carried out the thermomechanical studies and J.M.L.R was responsible for single lap joints tests. All authors drafted the manuscript, read and approved the final manuscript.

\section{Acknowledgements}

We acknowledge and thank the team of RECAT - UFF for DSC and TGA analysis, the LADEQ - UFRJ for DMA analysis and CAPES for financial support.

Received: 13 August 2013 Accepted: 18 September 2013

Published: 23 December 2013

\section{References}

1. McAdams LV, Gannon JA (1991) In: Kroschwitz Jl (ed) High Performance Polymers and Composites. John Wiley \& Sons, Inc, pp 258-318

May CA (ed) (1988) Epoxy Resins Chemistry and Technology, 2nd edition. New York, Marcel Dekker, Inc

- McGarry FJ (1996) In: Arends CB (ed) In Polymer Toughening. Marcel Dekker, Inc, New York, pp 175-188

4. Banea MD, da Silva LFM (2010) Proceedings of the Institution of Mechanical Engineers 224 Part L: J. Materials: Design and Applications, pp 51-62

Lucas EF, Soares BG, Monteiro E (2001), p 366. e-papers

Sperling LH (2006) Introduction to Physical Polymer Science. John Wiley and Sons, Inc, p 880

. da Silva LFM, Adams RD (2007) Int. J. Adhes. Adhes. 27:362-379

8. da Silva LFM, Adams RD (2005) J. Adhes. Sci. Technol. 19:109-141 
9. Grant LDR, Adams RD, da Silva LFM (2009) Int. J. Adhes. Adhes. 29:535-542

10. Banea MD, de Sousa FSM, da Silva LFM, Campilho RDSG, Bastos de Pereira AM (2011) J. Adhes. Sci. Technol. 25:2461-2474

11. Banea MD, da Silva LFM, Campilho RDSG J. Adhes. Sci. Technol.:1-15

12. Osanai KR (2013) Reis, J.M.L. Mater Sci Forum 758:119-124

13. (2012) ASTM D 3418-12. Standard Test Method for Transition Temperatures and Enthalpies of Fusion and Crystallization of Polymers by Differential Scanning Calorimetry

14. Barral L, Cano J, López AJ, Lopez J, Nogueira P, Ramírez C (1995) Thermochim. Acta. 269-270:253-259

15. da Costa Mattos HS, Sampaio EM, Monteiro AH (2011) Int. J. Adhes. Adhes. 31:446-454

16. da Costa Mattos HS, Sampaio EM, Monteiro AH (2012) Compos Part B- Eng 43:1964-1969

doi:10.1186/2196-4351-1-6

Cite this article as: Souza and Reis: Thermal behavior of DGEBA (Diglycidyl Ether of Bisphenol A) adhesives and its influence on the strength of joints. Applied Adhesion Science 2013 1:6.

Submit your manuscript to a SpringerOpen ${ }^{\circ}$ journal and benefit from:

- Convenient online submission

- Rigorous peer review

- Immediate publication on acceptance

- Open access: articles freely available online

- High visibility within the field

- Retaining the copyright to your article 